\title{
DEVELOPMENT OF FULLY SUPERCONDUCTING 5 MW AVIATION GENERATOR WITH LIQUID HYDROGEN COOLING
}

\author{
Dmitry Dezhin $\bowtie$ \\ Department of Electrical Machines and Power Electronics ${ }^{1}$ \\ dezhind@gmail.com \\ Roman Ilyasov \\ Department of Electrical Machines and Power Electronics ${ }^{1}$ \\ ${ }^{1}$ Moscow Aviation Institute \\ 4 Volokolamskoe highway, Moscow, Russia, 125993
}

$\triangle$ Corresponding author

\begin{abstract}
The use of liquid hydrogen as a fuel will be inevitable in the aviation of the future. This statement means that manufacturers will also implement liquid hydrogen for cooling all superconducting aviation equipment of an electric propulsion system. The development of fully electric aircraft is the most promising solution in this case. Scientists from the Department of electrical machines and power electronics of Moscow aviation institute have conducted calculations and theoretical researches of critical specific mass-dimensional parameters ( $\mathrm{MW} /$ ton and $\mathrm{MW} / \mathrm{m}^{3}$ at $21 \mathrm{~K}$ ) of fully superconducting aviation synchronous generator of the electric propulsion system. The results are in this article.

The article discusses the results 3D finite element modeling (FEM) simulation of a $5 \mathrm{MW}$ fully superconducting synchronous generator with combined excitation. Superconducting armature and axial excitation windings based on second generation high temperature superconductors (HTS-2G) are located on the stator, which makes it possible to contactlessness and the absence of sliding seals. A dry gap will reduce gas-dynamic losses and increase the nominal peripheral speed of the rotor. The use of liquid hydrogen as a coolant makes it possible to significantly increase the linear load of the generator, and high current densities to reduce the cross-sectional area of the coils, which will make it possible to place them in individual cryostats in the future. Individual cryostats will allow to remove the heat release of magnetic losses from the cryogenic zone and reduce the consumption of refrigerant. For the purpose of internal redundancy of the HTS coils, the machine has a complete set of reserve winding made of ultrapure aluminum, also cooled by liquid hydrogen. If the superconducting coils get out of the stand, the generator will provide $15 \%$ power on standby.

Keywords: superconducting electrical machine, liquid hydrogen cooling, high temperature superconductors (HTS), aircraft power systems.
\end{abstract}

DOI: $10.21303 / 2461-4262.2022 .001771$

\section{Introduction}

Development of the electric propulsion systems for future electric aircrafts is one of the most important challenges in aviation science. Currently, advanced propulsion systems for future electric aircraft are being developed around the world [1-3]. Moving away from fossil fuels and transition to clean hydrogen energy involves the use of electric machines to produce thrust in future aircraft. However, such a transition also requires new electrical equipment that can operate at cryogenic temperatures of liquid hydrogen, which will be used as fuel for future aircraft. This equipment includes aircraft generators, which are the main source of electrical energy on an aircraft. The article describes an approach to the development of the fully superconducting $5 \mathrm{MW}$ aviation generator with liquid hydrogen cooling for future aircrafts, which is being carried out at the Moscow Aviation Institute.

The mass and dimensions of an electric machine of a pre-adjusted power depend only on three central values: linear load $\left(A_{l}\right)$, electric induction in the operating gap $\left(B_{\delta}\right)$, and the rotor rated speed $(n)$. The diameter of the armature boring $\left(D_{a}\right)$ is proportional to:

$$
D_{a} \sim \sqrt[3]{\frac{1}{A_{l} \cdot B_{\delta} \cdot n / 60}}
$$


The linear load for superconducting windings depends on the wire's current-carrying capacity, which depends on the coolant's temperature. According to preliminary estimates, the linear load can be in the range of 80,000-600,000 A/m. The main determining criterion for the critical linear load is that the armature reaction will not affect permanent magnets' demagnetization. This statement applies to the case then there is a construction with combined excitation from superconducting windings and rare-earth permanent magnets.

The mechanical strength of the rotor is the limiting factor of its critical speed. The standard electrical frequency is $400 \mathrm{~Hz}$ for AC aircraft electric machines. The electric frequency sets the rotor speed to a single-digit value of $12000 \mathrm{rpm}$ when the number of poles is four $(p=4)$. Increasing the rotor speed is possible if to reduce the number of poles to two $(p=2)$. But this is not a rational solution because it will lead to a significant increase in the thickness of the stator yoke. An increase in the rotor speed is also possible with an increase in the current frequency, which is also an irrational solution. It will increase the magnetic losses and losses in the superconducting armature winding.

It is possible to reduce the size of an electric machine's active zone by increasing the electric induction in the operating gap. If to do this, it is necessary to increase the magnetomotive force (MMF) excitation and, at the same time, the width of the magnetic circuit. In this case, an increase in the MMF excitation will lead to its saturation, which will lead to an increase in magnetic losses if the stator tooth width remains the same. Therefore, increasing electric induction in the operating gap is also not an effective way to reduce the active zone size. It is possible to simultaneously solve both problems using the second-generation high-temperature superconductivity (HTS) tapes as excitation winding wires. The high current-carrying capacity of the HTS wire and, as a result, the current density of the superconducting winding makes it possible to reduce the size of its window, which will allow to free up space for the magnetic circuit tooth.

It is possible to conclude that using superconducting armature windings and excitation windings is a non-alternative method that can significantly reduce the active zone size and the mass of the entire electric machine.

Besides, when the temperature of the HTS tape decreases, its current-carrying capacity increases at the same time, and it also improves the efficiency of this method.

\section{Materials and methods}

Among the many variants of electric machines, there are several types of fully superconducting ones promising in terms of use at liquid hydrogen temperature. These are synchronous magnetoelectric machines and machines with electromagnetic excitation.

A fully superconducting electric machine with electromagnetic excitation, with the secondgeneration HTS tape excitation winding on the rotor, has several significant disadvantages:

- brush contacts for power supply of superconductive excitation winding or sub-exciter stage, to ensure contactless of an electrical machine and the possibility the excitation current regulating;

- rotating cryostat rotor with a refrigerant supply system with sliding seals or high hydrodynamic losses in the gap, if there is a standard cryostat («wet gap»).

If to consider an electric machine with electromagnetic excitation, in which only the armature winding located on the stator is superconducting, then this solution has the following disadvantages:

- it isn't easy to adjust;

- the linear load is limited because the HTS winding, especially at the boiling point of liquid hydrogen, has a high current-carrying capacity, MMF, and, as a result, a significant armature reaction. The armature reaction completely demagnetizes the permanent inductor magnets in the case of an inductive load.

Thus, a fully superconducting electric machine (FSEM) with combined excitation is considered $[4,5]$ as the leading and most promising solution. In this machine, all superconducting windings are installed on the stator. This solution allows to avoid sliding contacts, rotating cryostat on the rotor, and use dry working gap.

One of the essentialoperational characteristics of electric aircraftmachines is reliability [6-10]. A fully superconducting electrical machine based on the second generation HTS tapes [11, 12], 
created at the moment in the world, did not pass the service life tests. Therefore, the questions of survivability, reliability, and life cycle have not been experimentally confirmed yet. To ensure the electric machine's operation at $15 \%$ of the rated power, in emergency mode with a complete failure of all superconducting windings, the machine's design provides backup sets of resistive windings.

In this case, the backup resistive windings will be cooled with liquid hydrogen, making it possible to use ultra-pure aluminium conductors as backup windings. These types of conductors are cryogenic conductors. Cryogenic conductors are resistive electrical conductors with significantly low specific electrical resistivity at low liquid hydrogen or helium temperatures. Typical cryogenic conductors are copper and aluminium.

Ultra-pure copper is more effective in electrical conductivity way than ultra-pure aluminium. In any case, lighter aluminium wires are preferable for electric aircraft machines much more. Besides, it is possible to use aluminium wires without coolant at all. In this case, wires are can be cooled by air blowing, but this leads to a significant decrease in the current-carrying capacity. This situation makes it possible to use an electric machine even if the cryogenic feeding system fails, for example, in an emergency landing situation or struggle for survivability (response procedures). In this scenario, the generator provides power to the system's essential elements, and the engine allows for continuous slow-speed movement or rapid maneuver. Our scientists have conducted calculations and researches for the most promising full superconducting electric machine with combined excitation $[4,5]$. Series of analytical calculations and finite element method (FEM) simulation have been conducted to evaluate the possibility of creating a high-power aviation synchronous generator of the electric propulsion system for fully electric aircraft. The calculated cross-section sketch is in Fig. 1. The results of analytical calculations are in Table $\mathbf{1}$.

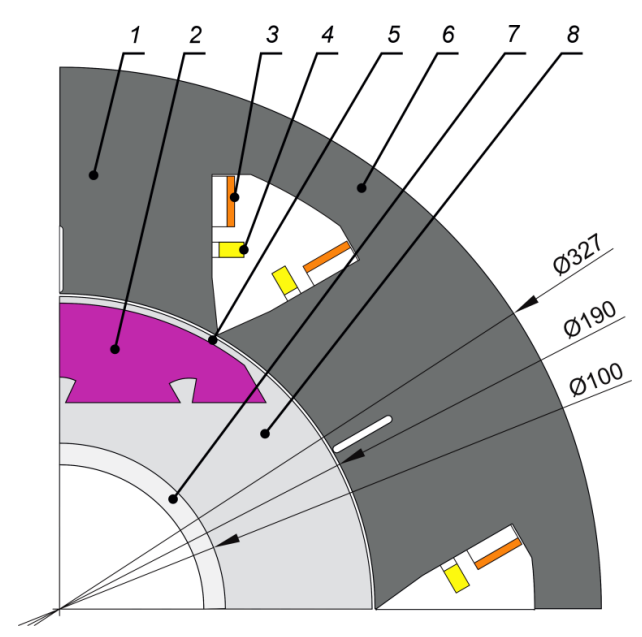

Fig. 1. Cross-section sketch of HTS generator active zone:

1 - stators teeth; 2 - permanent magnets; 3 - HTS armature windings; 4 - backup armature windings; 5 - bandage (ferromagnetic, part of electrical steel sheets); 6 - stator yoke; 7 - shaft;

$$
8 \text { - ferromagnetic poles }
$$

Fig. 1 shows the actual ratio of the size of the superconducting windings to the size of the magnetic circuit. In classic electric machines with traditional cooling, the groove's size with resistive windings is comparable in size to the tooth's size. The high current-carrying capacity of superconducting tapes, especially at the boiling point of liquid hydrogen, makes it possible to significantly reduce the cross-sectional area of the windings (3) and expand the teeth (1) to ensure the flow of greater magnetic flux.

This solution allows for increasing the gap's magnetic induction value, avoiding the magnetic circuit's oversaturation. It is possible to use backup windings (4) made of ultra-pure aluminum of small size as long as they are cooled with liquid hydrogen and have a high current-carrying capacity. Besides, the emergency mode of failure of superconducting windings implies operation at reduced power. The reduced power in our calculations is $15 \%$ of the rated power (5 MW). 
Table 1

Parameters of 5 MW fully HTS generator

\begin{tabular}{|c|c|c|}
\hline Parameter & Value & Unit \\
\hline Rated active power & 5000 & $\mathrm{~kW}$ \\
\hline Rotor's speed & 12000 & rpm \\
\hline Electromotive force (EMF) idle running & 292 & $\mathrm{~V}$ \\
\hline Inductive resistance along $d$-axes & 0.04 & Ohm \\
\hline The number of turns of the armature winding phase & 16 & turn \\
\hline Rated voltage phase & 227 & V \\
\hline Phase current & 3730 & A \\
\hline Real active power & 5001 & $\mathrm{~kW}$ \\
\hline Rated mechanical moment & 3.976 & $\mathrm{kN} \cdot \mathrm{m}$ \\
\hline Rotor's circumferential velocity (rated) & 118.25 & $\mathrm{~m} / \mathrm{s}$ \\
\hline Rotor's circumferential velocity (max) & 141.9 & $\mathrm{~m} / \mathrm{s}$ \\
\hline Diameter of the stator boring & 190 & $\mathrm{~mm}$ \\
\hline Active stator packs length & 120 & $\mathrm{~mm}$ \\
\hline Outside diameter (yoke's backside) & 327 & $\mathrm{~mm}$ \\
\hline External cryostat's size (total) & 383 & $\mathrm{~mm}$ \\
\hline Total axial length (without shaft overhang) & 336 & $\mathrm{~mm}$ \\
\hline Electric frequency & 400 & $\mathrm{~Hz}$ \\
\hline Number of poles & 4 & - \\
\hline Induction in the gap (average) & 1.23 & Tesla \\
\hline Linear armature load & 600000 & $\mathrm{~A} / \mathrm{m}$ \\
\hline Excitation winding current & 3573 & A \\
\hline Magnetomotive force (rated load) & 155326 & - \\
\hline Magnetomotive force (MMF) idle running & 8229 & A/turn \\
\hline Field winding wire length & 143 & $\mathrm{~m}$ \\
\hline Armature winding Wire Length & 70 & $\mathrm{~m}$ \\
\hline Total losses and heat gains & 1568 & W \\
\hline Hydrogen evaporation consumption & 12.6 & $\mathrm{~kg} / \mathrm{h}$ \\
\hline Electric machine efficiency & 99.97 & percent \\
\hline Specific total mass power & 36.44 & MW/ton \\
\hline Specific volumetric power & 115.42 & $\mathrm{MW} / \mathrm{m}^{3}$ \\
\hline Total volume of the machine & 43 & 1 \\
\hline Total mass & 137 & $\mathrm{~kg}$ \\
\hline
\end{tabular}

Table 1 shows that the calculated generator has unique mass-dimensional characteristics and high efficiency. Calculated liquid hydrogen discharge will be 12.6 kilograms per hour if to use it as a coolant. Thus, there is a tenfold margin for the liquid hydrogen fuel discharge, taking into account its calorific value and the fact that this fuel will be used in the power unit with an efficiency close to one hundred percent.

The calculated generator's characteristics are in Fig. 2, $\boldsymbol{a}, \boldsymbol{b}$. The generator's angular characteristics (Fig. 2, a) indicate an excellent overload capacity. Besides, the power factor value is practically not reduced when the power is increased to $7 \mathrm{MW}$.

The generator's external characteristic, without compensation for the armature reaction by increasing the excitation current, is in Fig. 2, $\boldsymbol{b}$. The form of voltage drop with an increase in the nominal phase current has a traditional format typical for an unregulated synchronous magnetoelectric generator.

In the presented construction of a synchronous generator with combined excitation, the voltage drop with an increase in the phase current can be easily compensated by increasing the 
current in the superconducting excitation winding. Thus, it is possible to ensure the rated voltage's constancy over a wide range of operating currents and operating powers.
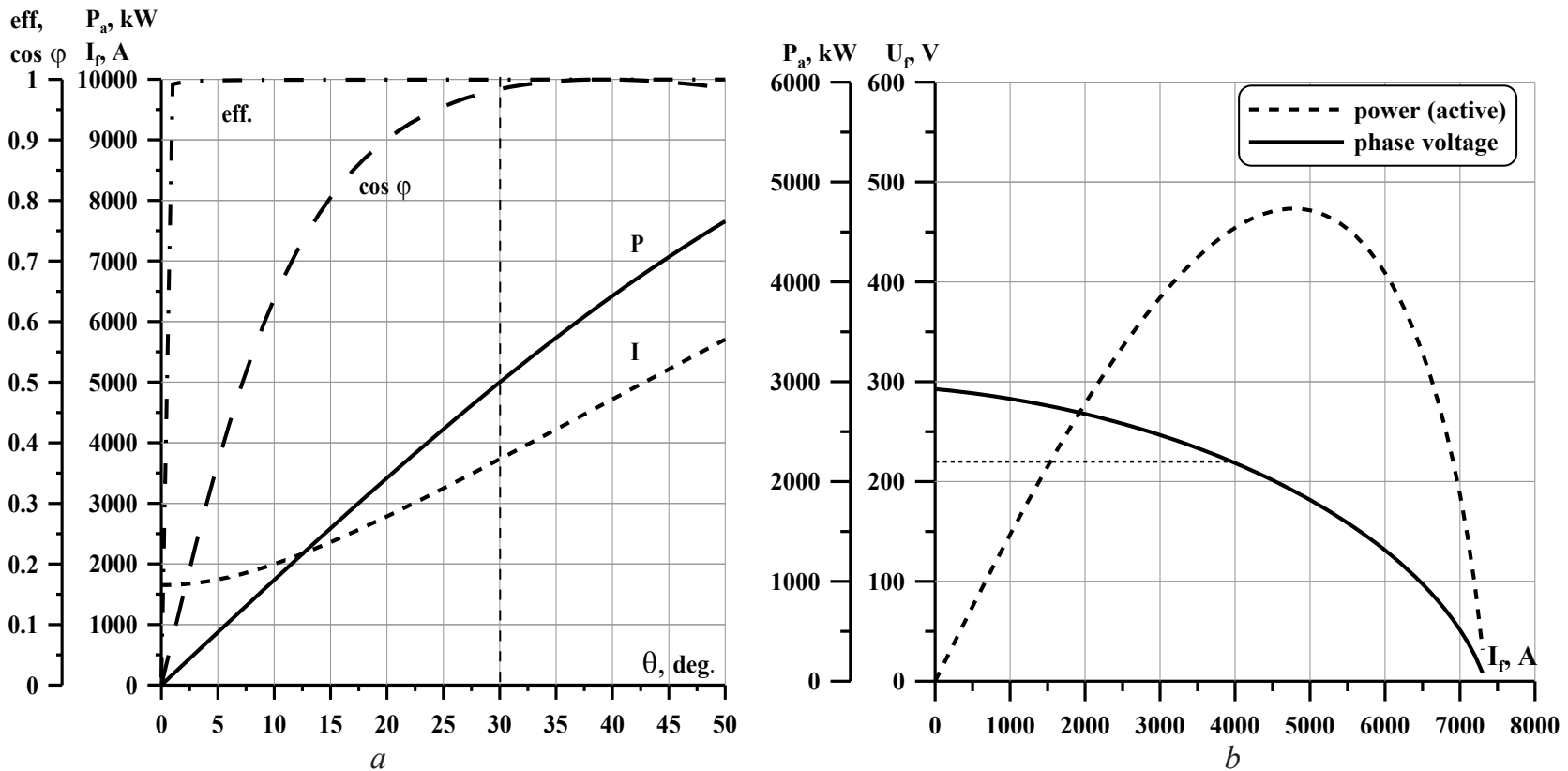

Fig. 2. The generator's characteristics: $a$ - angular; $b$ - load (rated field current)

It should be mentioned that a superconducting excitation winding can effectively compensate for the demagnetizing effect of superconducting armature windings. This statement makes the class of superconducting synchronous electric machines with pure magnetoelectric excitation irrational.

Circle diagram of the mass and heat distribution in elements of a fully superconducting electric machine with combined excitation are in Fig. 3.

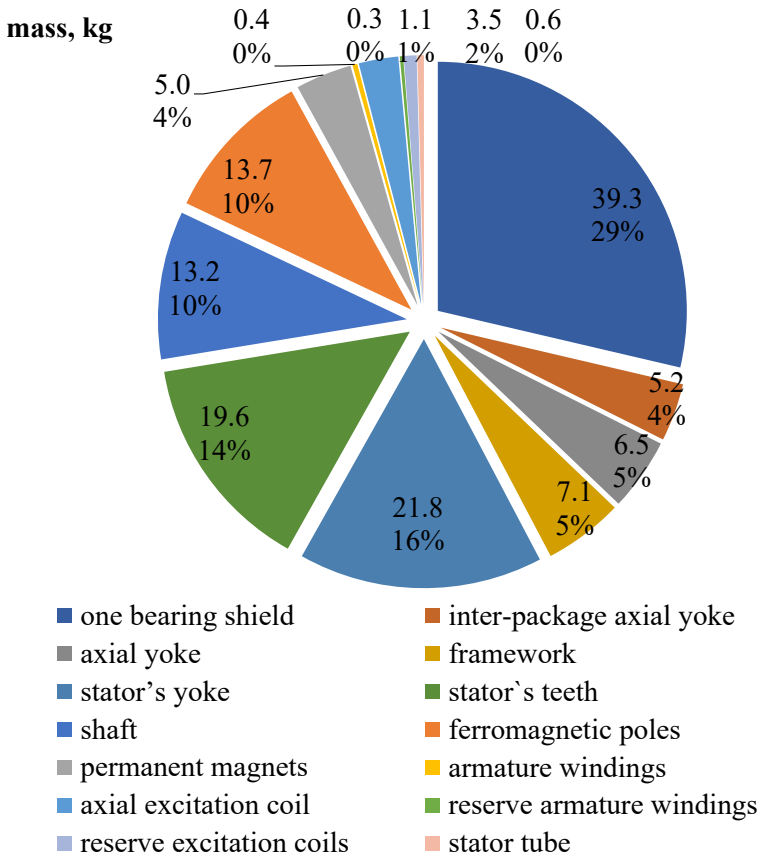

$a$

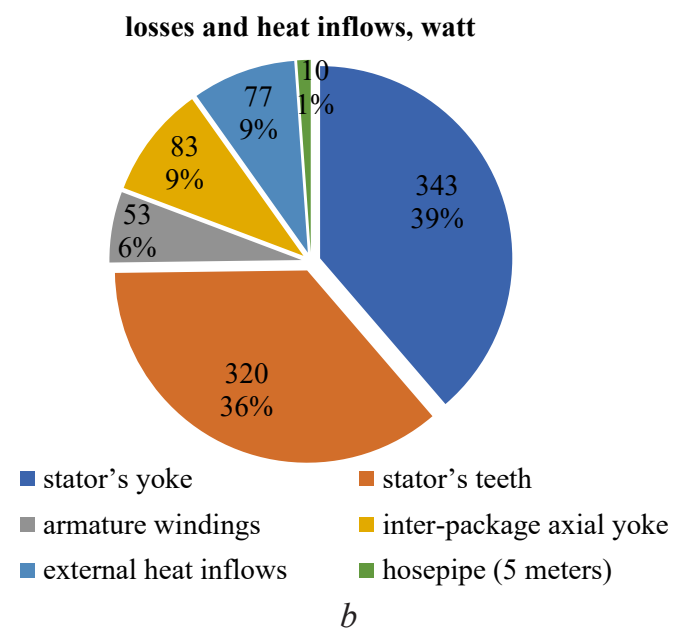

Fig. 3. HTS generator's diagrams: 
Fig. 3, $\boldsymbol{a}$ shows the percentage of the generator's elements mass to the developed synchronous generator's total mass. The diagram indicates that the most outstanding contribution to the mass is made by bearing shields. In addition to their structural (load-carrying) function, these shields also serve as axial magnetic circuits.

Fig. 3, $\boldsymbol{b}$ shows the losses and heat flows to the cryostat's cold zone. It is possible to see that the most significant losses occur on the anchor packages' yoke and its teeth. Losses in the inter-pack yoke are insignificant since it is made of a twisted magnetic circuit of electrical silicon steel. Electrical losses in the armature winding made of $2^{\text {nd }}$ generation HTS tape are negligible due to the wire's small total length.

It's evident that magnetic losses make the main contribution to heat generation, and it is typical for fully superconducting electric machines.

If it is necessary, magnetic losses can be reduced by using special electrical steels with a high silicon content and thinner sheet (less than $0.35 \mathrm{~mm}$ ) in packages.

It is possible to significantly reduce external heat flows by using a high-quality outer sheet-vacuum cryostat. It is assumed in our calculations that the cryostat would be made of rolled cryogenic isolation - Cryogel- $Z^{\circledR}$, with a total thickness of $20 \mathrm{~mm}$. Despite the relatively high thermal conductivity of rolled cryogenic isolation $(14 \mathrm{~mW} /(\mathrm{m} \cdot \mathrm{K}))[13]$, it has a low mass and high operating characteristics.

\section{Results and discussion}

\section{1. Results of numerical simulation of $5 \mathrm{MW}$ HTS generator}

Calculations of magnetic fields in three-dimensional space were performed by using FEM modeling (COMSOL Multiphysics software). The results of FEM modeling fully confirmed the results of earlier analytical calculations.

Fig. 4 shows isometric pictures of the magnetic fields' distribution in the designed generator at idle running mode. Fig. 5 shows the distribution of magnetic fields in the cross-sections of the generator at idle running mode.

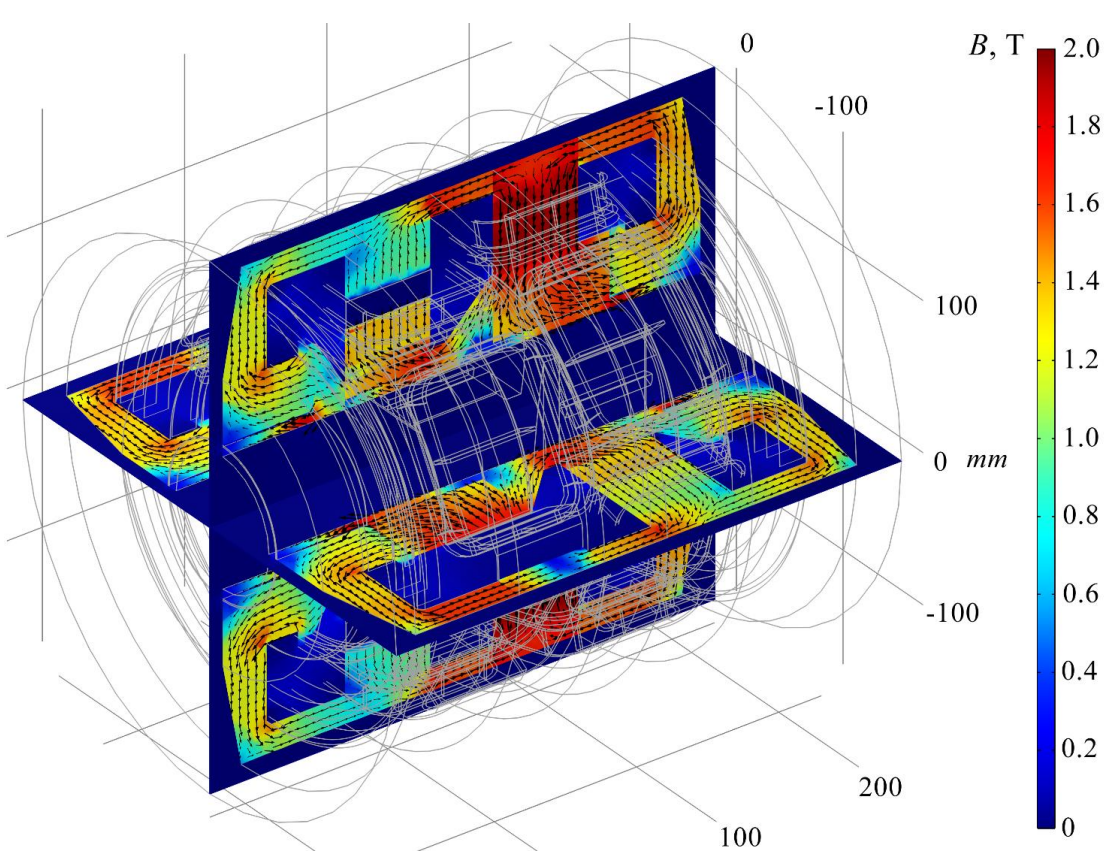

Fig. 4. Isometric picture of the magnetic fields' distribution with no load

Fig. 6 shows the isometric picture of the magnetic fields' distribution in the working gaps. This figure shows that the generator does not have end-pole scattering fluxes at idle running mode because there is no decrease in the magnetic field at the packets' edges. 


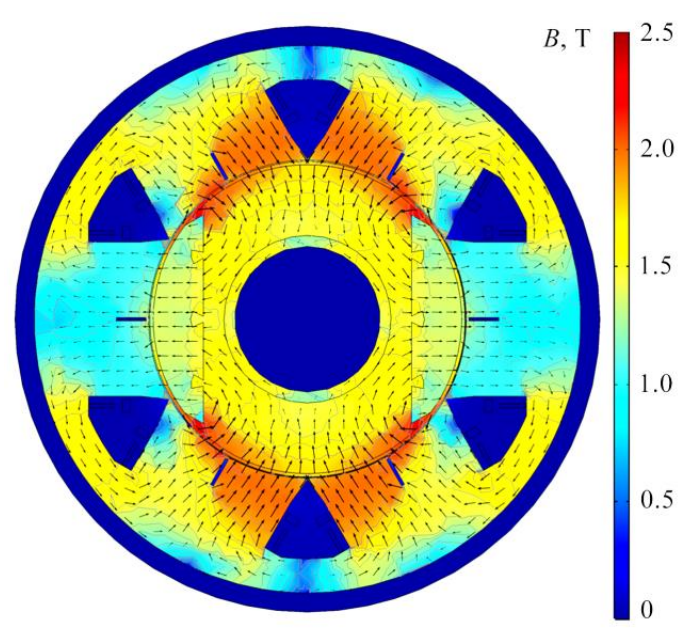

$a$

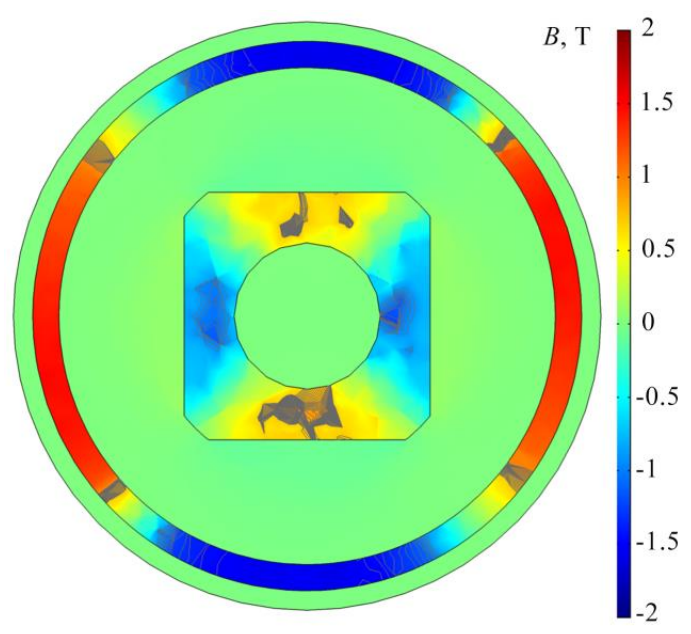

$c$

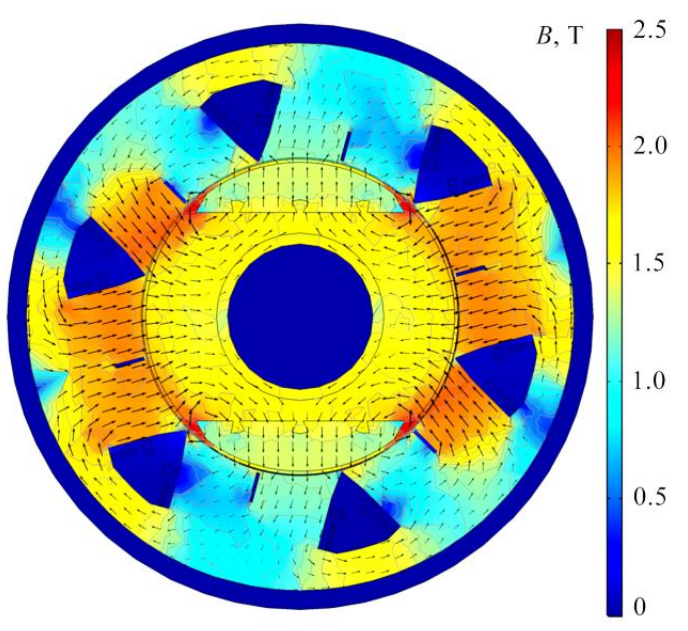

$b$

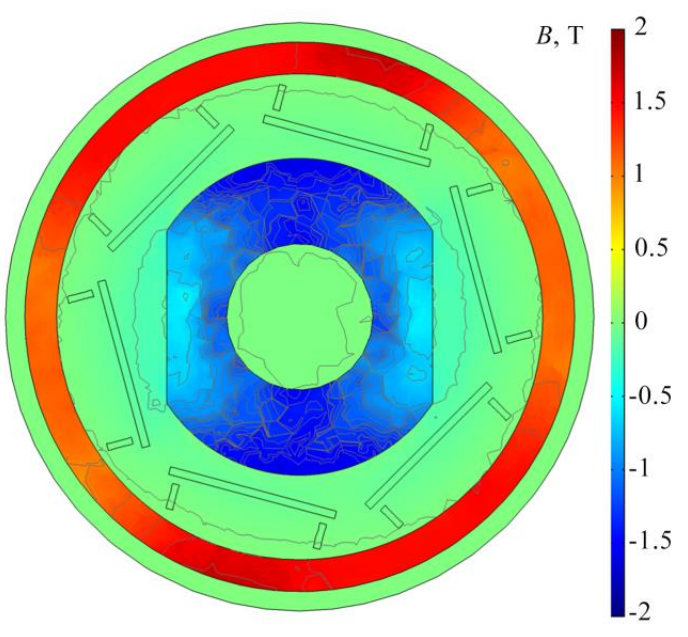

$d$

Fig. 5. Magnetic fields' distribution of cross-section (with no load): $a$-in the Stack 1; $b$ - in the Stack 2; $c$-in the inter-package axial yoke; $d$-in the axial yoke of bearing shield

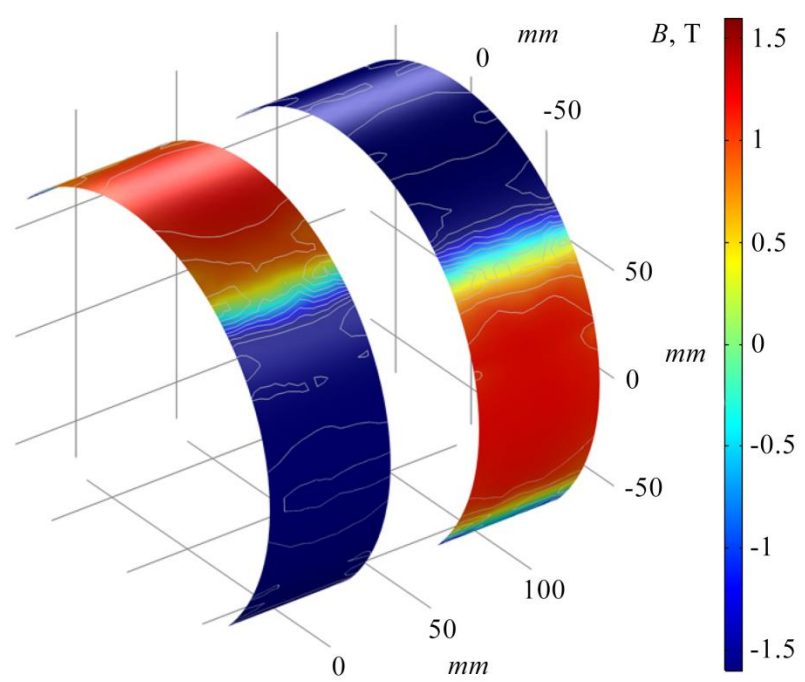

Fig. 6. Magnetic fields' distribution in the air gaps of the HTS's stators of the superconducting generator at idle running mode 
Fig. 7 shows the magnetic fields' distribution in the generator's cross-sections at the rated load mode.

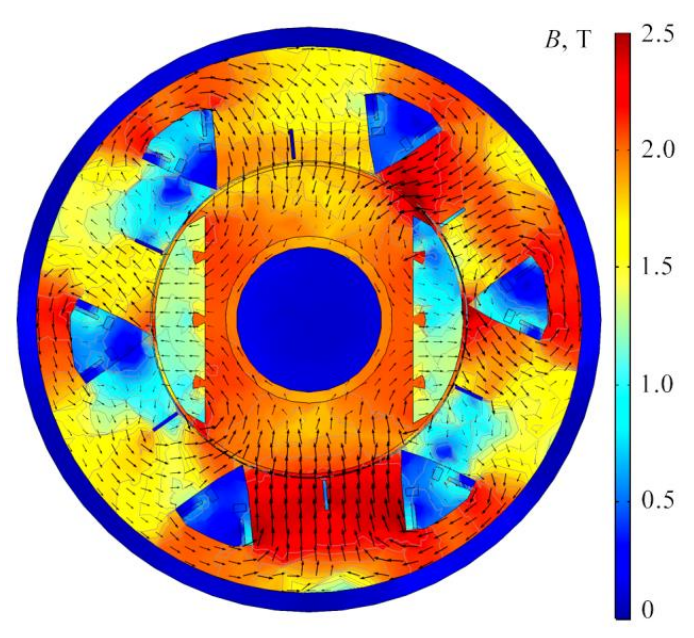

$a$

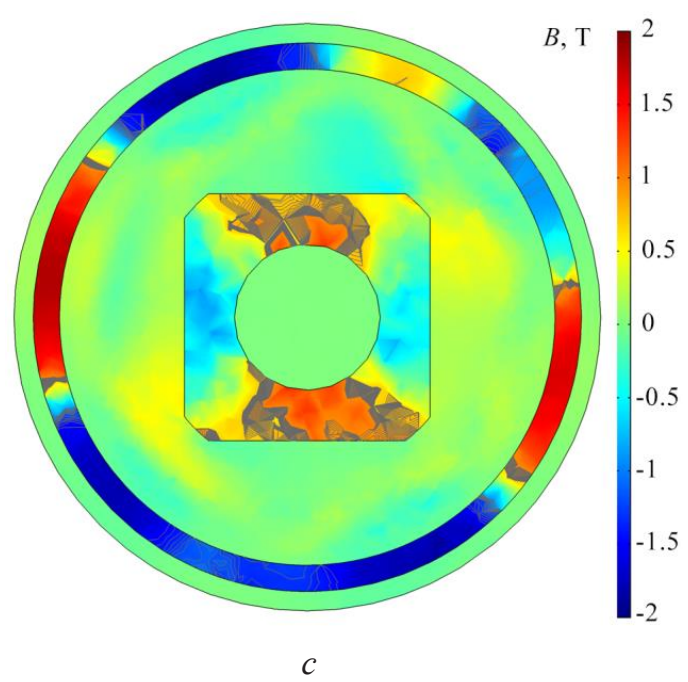

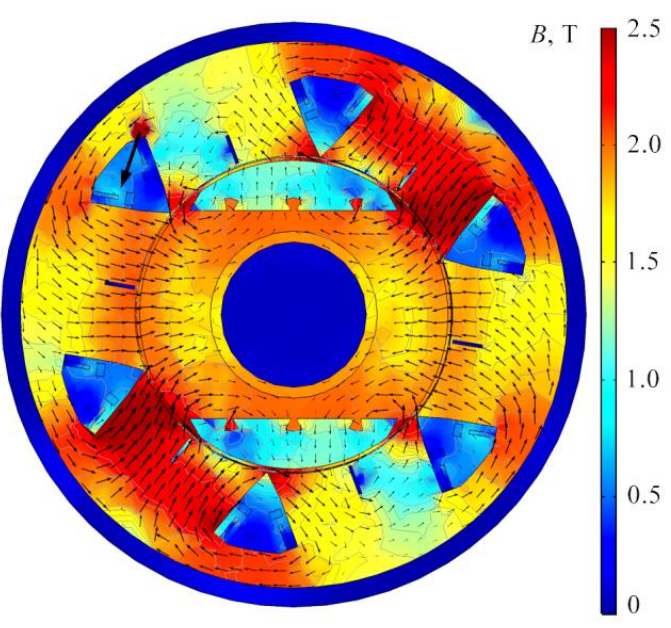

$b$

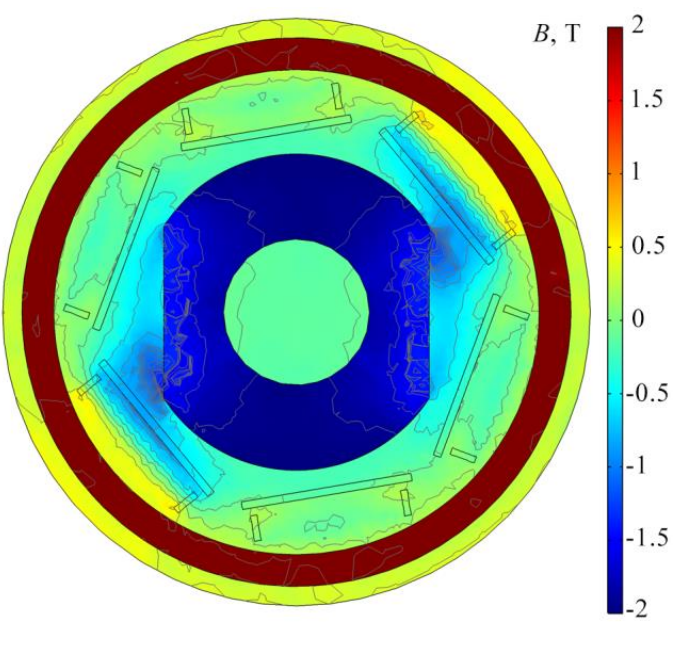

d

Fig. 7. Magnetic fields' distribution of cross-section (with rated load): $a$ - in the Stack 1; $b$ - in the Stack $2 ; c-$ in the inter-package axial yoke; $d$ - in the axial yoke of bearing shield

Fig. 8 shows the distribution of the magnetic field in the air gap. The graph shows the contribution of the HTS axial field coils (green) and high-coercive permanent magnets (blue) to the total (red) magnetic induction in the working gap of the HTS generator. Solid lines show the phase EMF of the left package's armature winding, dotted lines - the right one.

The shapes of the graphs and their values averaged over the length of the pole arc indicate that the values of magnetic induction in the gap opposite the ferromagnetic poles (the flux from the superconducting axial field windings) are $1 \mathrm{~T}$ greater than the values of magnetic induction opposite the poles with permanent magnets. Numerical calculations have shown (Fig. 8) that the pole-unsymmetrical form of induction in the working gap does not lead to an asymmetry in the EMF amplitude induced in the armature winding. This fact indicates that the flux linkages with the armature winding coils from two adjacent poles are added and averaged. The stator's wide teeth, which occupy about $97 \%$ of the pole opening space, do not reach saturation $(1.8 \mathrm{~T})$, making it possible to achieve an average value of induction in the gap equal to $97 \%$ of the average value of induction in the tooth. Such a result can only be obtained using a narrow HTS armature winding with a high current carrying capacity at cryogenic (hydrogen) temperatures. 
In traditional electric machines with a resistive armature winding, the tooth takes up approximately the same amount of space $(50 \%)$ as the groove with a copper winding. This solution reduces the maximum possible average induction in the working gap by half, compared to the tooth's induction.

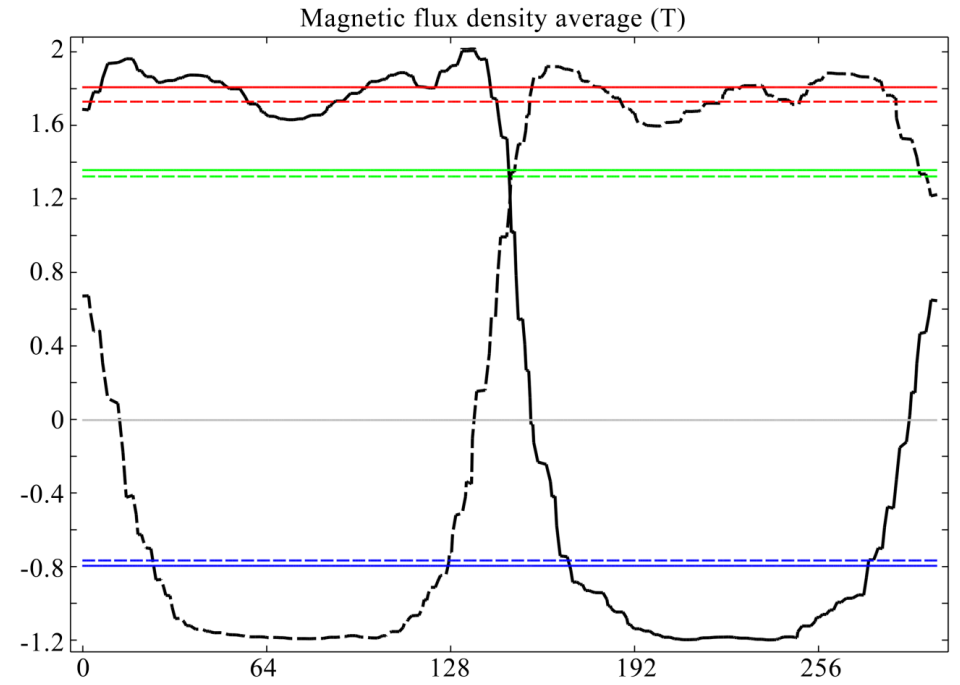

Fig. 8. The average induction of the magnetic field (tesla) in the air gap

The decrease in the induction in the gap opposite the poles with permanent magnets is due to the demagnetizing effect of the superconducting field windings and the pole scattering of the flow along with the ferromagnetic bandage of the rotor. Without the scattering of the magnetic flux from permanent magnets, with a pole opening equal to the pole fission, the induction's shape would be close to a rectangle. The demagnetizing effect of superconducting axial field windings can be reduced by increasing the permanent magnet's thickness, which has a small relative magnetic permeability (close to one). It is also possible to reduce the demagnetizing effect by reducing the thickness of the ferromagnetic bandage. Another unconventional way to smooth out pole asymmetry in width is to use the pole opening coefficient for permanent magnets of more than 1.

Problems of quality of generated electricity are relevant mainly for distributed AC power supply systems that have essential consumers sensitive to the slightest changes in network parameters. Let's believe that the aviation fully superconducting electric machine with a capacity of $5 \mathrm{MW}$ is not designed to work on a general on-board network, with the standard ability to power low-current on-board equipment.

Let's also believe that it is impossible to create a mechanical drive of constant speed for an aircraft with similar power and speed. This statement implies that the developed device's primary application field is a floating frequency direct-drive generator for the electric propulsion system's DC power network. When the generator runs on a rectifier, the requirements for the generated electricity quality are less strict.

The angular shift of two sets of three-phase windings located on adjacent packages is performed by physically rotating one package relative to the other.

The form of traditional generators' flux linkages depending on the rotor's angle rotation is in Fig. 9, $\boldsymbol{a}$.

The relative form of the EMF phases of the developed superconducting generator's armature windings and the voltage rectification result is in Fig. 9, $\boldsymbol{b}$.

The phase shift should usually be 30 electric degrees to improve rectified voltage quality (7). The graphs (Fig. 9) show that the ripple coefficient at idle running and without filters does not exceed traditional generators' values. Ripples are smoothed by the action of the armature reaction when operating at rated power. 


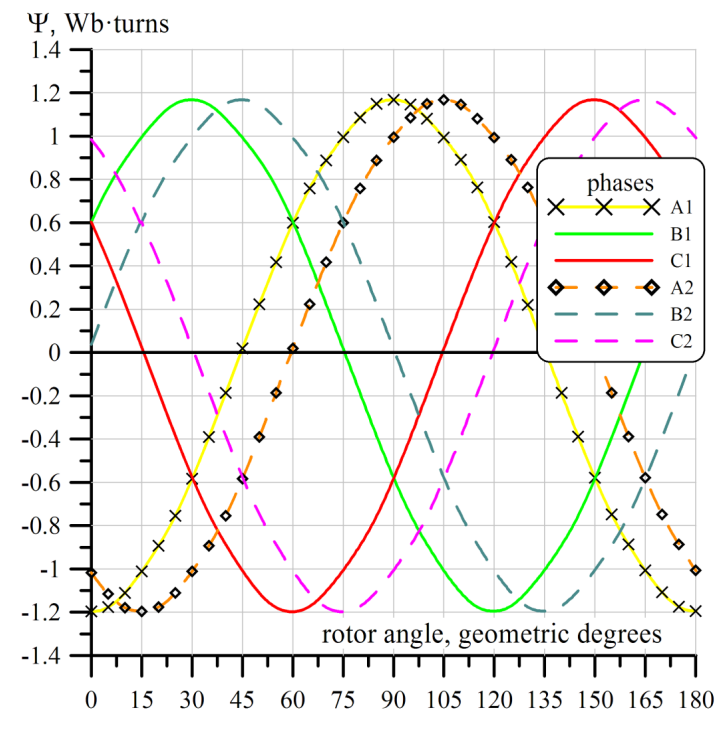

a

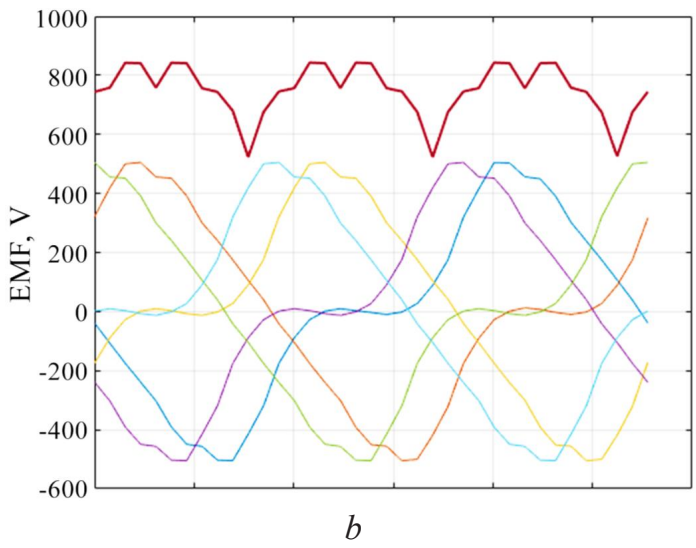

Fig. 9. Connection of the flux linkage with two three-phase armature windings (shifted by 30 electric degrees) with the form of the generated EMF:

$a$ - flux linkages' form with the traditional generator's armature windings phases (with shifted windings); $b$ - forms of EMF in the armature windings' phases and the form of the rectified voltage

\section{2. Discussion}

Numerical simulations have shown that the proposed HTS generator scheme can provide outstanding results for this kind of machines in terms of specific power and contactlessness. It should be noted that the results of modeling the HTS generator were obtained taking into account the strong saturation of the magnetic circuit and the ideal properties of electrical materials. The geometry of the generator active zone has also been idealized to a certain extent.

To check the obtained characteristics of the 5 MW HTS generator, it is planned to produce its experimental small-scale model for $100 \mathrm{~kW}$ in the future. At the manufacture of this electrical machine, electrical materials will be used, the properties of which will make it possible to refine the material models of materials in the computational problem and check the reliability of numerical calculations.

The use of liquid hydrogen as a refrigerant makes it possible to significantly increase the current-carrying capacity of HTS tapes, increase the linear load of an electric machine, efficiency, specific power, and significantly reduce its overall dimensions and weight. The boiling point of liquid hydrogen makes it possible to use ultrapure aluminum as cryoconductors for backup windings, since its electrical resistivity at this temperature is lower than that of copper. Ultimately, 
the mass of high-power aircraft generators greatly affects the main economic parameter of air transportation - the fuel efficiency.

The $5 \mathrm{MW}$ drives, such as propeller drives, must have their own dedicated power supplies. Connecting them to the general electrical network of the aircraft will lead to critical changes in the quality of the network parameters in the event of a change in the load. For example, fluctuations in the voltage level, unacceptable deviation of the voltage waveform, changes in the electrical frequency and other parameters of the power quality of the aircraft network. These changes can have a critical impact on all electrical equipment connected to this network.

Electric machines of the megawatt class with high specific indicators (relatively small mass and size) are most promising on mobile objects with an electric propulsion system: locomotives, airplanes, ships, large trucks, etc. For these mobile objects, superconducting electric machines with liquid-hydrogen cooling are no alternative. Currently used gas turbine engines of such power have a relatively low efficiency, high noise, low environmental friendliness.

\section{Conclusion}

As a result of the conducted research, an original design of a $5 \mathrm{MW}$ superconducting aviation generator with cryogenic liquid hydrogen cooling was developed. Its main feature is higher reliability in comparison with SC generators of alternative designs. High reliability is achieved by duplicating the HTS coils with conventional copper coils, which allows the generator to remain operational even with the disappearance of cryogenic cooling. Also, the lack of a rotating cryostat on the rotor has a positive effect on improving reliability. Carried calculations have shown that a $5 \mathrm{MW}$ superconducting generator at 12,000 rpm has outstanding specific mass-dimensional parameters of $36 \mathrm{MW} /$ ton and $115 \mathrm{MW} / \mathrm{m}^{3}$. It should be noted that most of the tested superconducting and traditional electric machines had a specific power of less than $5 \mathrm{~kW} / \mathrm{kg}$ (MW/ton). The indicators achieved in the developed superconducting aviation generator allowing it to use in transport facilities, including aviation ones. At the next stages of development, it is necessary to experimentally test the proposed solutions and quantitative indicators of the generator, including in order to identify the difficulties associated with cryogenic hydrogen cooling.

\section{Acknowledgements}

The Study was carried out with the financial support of a project by the Russian Federation represended by the Ministry of Education and Science of the Russian Federation, agreement $\mathrm{N}^{\circ} 075-15-2020-770$.

\section{References}

[1] Ansell, P. J., Haran, K. S. (2020). Electrified Airplanes: A Path to Zero-Emission Air Travel. IEEE Electrification Magazine, 8 (2), 18-26. doi: https://doi.org/10.1109/mele.2020.2985482

[2] Barzkar, A., Ghassemi, M. (2020). Electric Power Systems in More and All Electric Aircraft: A Review. IEEE Access, 8, 169314-169332. doi: https://doi.org/10.1109/access.2020.3024168

[3] Wheeler, P., Sirimanna, T. S., Bozhko, S., Haran, K. S. (2021). Electric/Hybrid-Electric Aircraft Propulsion Systems. Proceedings of the IEEE, 109 (6), 1115-1127. doi: https://doi.org/10.1109/jproc.2021.3073291

[4] Dezhin, D., Dezhina, I., Ilyasov, R. (2020). Small-scale prototype of a fully HTS-2G six-phase induction electrical machine. Journal of Physics: Conference Series, 1559 (1), 012146. doi: https://doi.org/10.1088/1742-6596/1559/1/012146

[5] Dezhin, D., Dezhina, I., Ilyasov, R. (2020). Superconducting Propulsion System with LH2 Cooling for All-Electric Aircraft. Journal of Physics: Conference Series, 1559 (1), 012143. doi: https://doi.org/10.1088/1742-6596/1559/1/012143

[6] Kovalev, K., Ivanov, N., Zhuravlev, S., Nekrasova, J., Rusanov, D., Kuznetsov, G. (2020). Development and testing of 10 kW fully HTS generator. Journal of Physics: Conference Series, 1559 (1), 012137. doi: https://doi.org/10.1088/1742-6596/1559/1/012137

[7] Gamble, B., Snitchler, G., Kalsi, S. S. (2006). HTS generator topologies. 2006 IEEE Power Engineering Society General Meeting. doi: https://doi.org/10.1109/pes.2006.1709646

[8] Go, B.-S., Sung, H.-J., Kim, C., Nam, G.-D., Jung, G.-E., Kim, S.-H., Park, M. (2020). Design and Feasibility Study of a Performance Evaluation System for a Large-Scale HTS Generator Under Short-Circuit Conditions. IEEE Transactions on Applied Superconductivity, 30 (4), 1-5. doi: https://doi.org/10.1109/tasc.2020.2981886 
[9] Sasa, H., Iwakuma, M., Yoshida, K., Sato, S., Sasayama, T., Yoshida, T. et. al. (2021). Experimental Evaluation of 1 kWclass Prototype REBCO Fully Superconducting Synchronous Motor Cooled by Subcooled Liquid Nitrogen for E-Aircraft. IEEE Transactions on Applied Superconductivity, 31 (5), 1-6. doi: https://doi.org/10.1109/tasc.2021.3055452

[10] Arabul, A. Y., Kurt, E., Keskin Arabul, F., Senol, İ., Schrötter, M., Bréda, R., Megyesi, D. (2021). Perspectives and Development of Electrical Systems in More Electric Aircraft. International Journal of Aerospace Engineering, 2021, 1-14. doi: https:// doi.org/10.1155/2021/5519842

[11] Zanegin, S. Y., Ivanov, N. S., Shishov, D. M., Shishov, I. M., Kovalev, K. L., Zubko, V. V. (2020). AC losses test of HTS racetrack coils for HTS motor winding. Journal of Physics: Conference Series, 1559 (1), 012142. doi: https://oi.org/10.1088/ 1742-6596/1559/1/012142

[12] Harca, I. M., Machaj, K., Tomkow, L., Glowacki, B. A. (2020). Magnetic flux in stacks of superconducting tapes of different architecture. Superconductor Science and Technology, 33 (11), 115004. doi: https://doi.org/10.1088/1361-6668/abbl1c

[13] Ilardi, V., Busch, L. N., Dudarev, A., Koettig, T., de Sousa, P. B., Liberadzka, J. et. al. (2020). Compression and thermal conductivity tests of Cryogel ${ }^{\circledR} \mathrm{Z}$ for use in the ultra-transparent cryostats of FCC detector solenoids. IOP Conference Series: Materials Science and Engineering, 756 (1), 012005. doi: https://doi.org/10.1088/1757-899x/756/1/012005

Received date 12.04.2021

(C) The Author(s) 2021

Accepted date 19.11.2021

This is an open access article

Published date 10.01.2022 under the Creative Commons CC BY license

How to cite: Dezhin, D., Ilyasov, R. (2022). Development of fully superconducting 5 MW aviation generator with liquid hydrogen cooling. EUREKA: Physics and Engineering, 1, 62-73. doi: https://doi.org/10.21303/2461-4262.2022.001771 